\title{
Tuberculosis Treatment Outcomes and Determinants among Patients Treated in Hospitals in Imo State, Nigeria
}

\author{
Chukwuma B. Duru1 ${ }^{*}$, Kenechi A. Uwakwe ${ }^{1}$, Chinomnso C. Nnebue ${ }^{2}$, Kelvin C. Diwe1, \\ Irene A. Merenu1, Chima 0. Emerole3 ${ }^{3}$ Chinedu A. Iwu", Chioma A. Duru ${ }^{5}$ \\ ${ }^{1}$ Department of Community Medicine, Faculty of Medicine, Imo State University, Owerri, Nigeria \\ ${ }^{2}$ Department of HIV Care/Community Medicine, Nnamdi Azikiwe University Teaching Hospital, \\ Nnewi, Nigeria \\ ${ }^{3}$ Department of Medical Services, Federal University of Technology, Owerri, Nigeria \\ ${ }^{4}$ Department of Community Medicine, Imo State University Teaching Hospital, Orlu, Nigeria \\ ${ }^{5}$ Rico Pharmaceutical Industries Limited, Onitsha, Nigeria \\ Email: *duruchukwuma16@yahoo.com
}

Received 19 May 2016; accepted 11 June 2016; published 14 June 2016

Copyright (C) 2016 by authors and OALib.

This work is licensed under the Creative Commons Attribution International License (CC BY).

http://creativecommons.org/licenses/by/4.0/

(c) (i) Open Access

\begin{abstract}
Introduction: Tuberculosis is a highly feared disease, known for centuries to affect, debilitate, impoverish large sections of the population and continues to ravage the world and especially the developing world. TB is curable and its effective treatment has shown a significant effect on the control of the disease. Methodology: This was a retrospective hospital based study carried out on records of 1025 TB cases, treated from 2009-2012 cohorts. A structured proforma was used to collect information from the TB registers, individual cards and folder records of the patients. Data were analyzed using a software package, EPI INFO version 7.1.3. Frequencies tables and summary indices were generated and chi-square was used to test association between variables where appropriate. P-value of $\leq \mathbf{0 . 0 5}$ was considered significant. Results: Most of the cases reviewed had pulmonary tuberculosis. $96.7 \%$ and majority $(86.3 \%)$ of them had sputum smear positive results at diagnosis. Majority, $79.7 \%$ of the patients were new cases and the treatment outcome showed a total success rate of $81.4 \%$, (cured, $46.3 \%$ and completed treatment, $35.1 \%$ ), default, $(9.8 \%)$, died $(6.5 \%)$ and failed treatment $(1.5 \%)$. Factors found to significantly affect treatment outcome in this study were; age, gender, educational status, religion, living with someone, treatment regimen, HIV status of patients and type of patient at presentation/diagnostic criteria, $p<$ 0.05. Conclusion: The success rate recorded in this study was below the set target by WHO, thus there was a need to put in place appropriate measures to improve the outcome of TB treatment in Imo State, Nigeria.
\end{abstract}

"Corresponding author.

How to cite this paper: Duru, C.B., Uwakwe, K.A., Nnebue, C.C., Diwe, K.C., Merenu, I.A., Emerole, C.O., Iwu, C.A. and Duru, C.A. (2016) Tuberculosis Treatment Outcomes and Determinants among Patients Treated in Hospitals in Imo State, Nigeria. Open Access Library Journal, 3: e2754. http://dx.doi.org/10.4236/oalib.1102754 


\title{
Keywords
}

\section{Tuberculosis, Treatment Outcome, Patients, Hospital, Imo State}

\author{
Subject Areas: Epidemiology
}

\section{Introduction}

Tuberculosis (TB) is a curable airborne infectious disease caused by a Mycobacterium Tuberculosis [1] [2]. It is a major public health problem throughout the world [3]. The disease primarily affects the lungs (Pulmonary TB) in greater than $80 \%$ of cases but can affect other parts of the body (Extra-pulmonary TB) in less than 20\% of cases, involving the kidneys, lymph nodes, spinal cord, the abdomen, skeletal system, pericardium, etc. [4] [5]. Africa and the entire world are facing the worst tuberculosis epidemic since the advent of the antibiotic era due to HIV pandemic [6]. Tuberculosis is a highly feared disease, known for centuries to affect, debilitate, impoverish large sections of the populations and continues to ravage the world and especially the developing world [7]. The disease is today one of the biggest infectious killers among young people and adults. Previously TB was the second leading cause of death annually from an infectious disease worldwide after HIV [8], but this trend has reversed since 2014, as TB now ranks alongside HIV as a leading cause of death worldwide [9] [10]. In 2014, 1.5 million people died of TB, of these 0.4 million people were HIV positive. Also in 2014, 1.2 million people died of HIV and this included the 0.4 million TB deaths among HIV positive people [9] [10]. Over 95\% of TB deaths occur in low and middle in some countries, and it's among the top 5 causes of death in women aged 15 to 44 years leading to a total of 480,000 deaths in women and 140,000 deaths in children [10] [11].

Globally in 2014 alone, there were an estimated 9.6 million incident cases of TB; 5.4 million among men, 3.0 million among women and 1.0 million among children. Also an estimated 480,000 people developed multi-drugresistant TB (MDRTB). The Millennium Development Goals (MDG) target of halting and reversing the TB epidemic has been met. TB incident has fallen by an average of $1.5 \%$ per year since 2000 and the death also rate dropped by 47\% between 1990 and 2015. An estimated 43 million lives were saved through TB diagnosis and treatment between 2000 and 2014 [9]-[11]. The WHO End TB strategy, adopted by World Health Assembly in May 2014, is a blue print for countries to end the TB Epidemic by driving down TB deaths, incidence, and eliminating catastrophic costs [11]. The largest number of new TB cases occurred in the South Eastern Asia and Western Pacific Regions, accounting for 58\% of new cases globally. However, Africa carried the most severe burden, with 281 cases per 100,000 populations in 2014 (compared with a global average of 133) [11]. Nigeria is ranked fourth among the 22 countries with the highest TB burden globally. According to 2014 global TB report, 570,000 new cases (323 per 100,000) occur in Nigeria annually. 590,000 prevalent cases were in the country and about 170,000 cases died the same year [10] [11]. Yet Nigeria did not meet the target assessment by WHO which was set from 1990-2015, which included reversal to falling incidence rate, 50\% reduction of prevalence of TB and mortality rate [10].

When individuals with infectious tuberculosis cough, sneeze, talk or spit, they expel TB bacilli into the air. $\mathrm{TB}$ is an airborne disease i.e. transmitted through the air by inhaling air contaminated with TB bacilli. Transmission is more intense in crowded, poorly ventilated spaces with little ambient sunlight as they increase the likelihood of inhalation of infectious TB bacilli present in the air. If not treated, a person with active pulmonary TB disease will infect, on average, between 10 and 20 people every year. Persons infected by $M$. tuberculosis but who have no symptoms of TB disease have what is known as latent TB infection. After infection, TB bacilli can lie dormant in the body for many years. If the immune system is compromised as in the case of HIV infection, malnutrition or other conditions the TB bacilli can cause active disease. Many factors influence the progression from infection to disease. The most important is HIV infection. Other factors include age, diabetes and cancer [5] [6]. Diagnosis of TB starts with early identification of a TB case and prompt initiation of treatment. This is important for TB control and reducing TB-related mortality, particularly in TB/HIV co-infected patients and other high risk groups. Diagnosis of tuberculosis depends on the identification of the tubercle bacilli in a clinical specimen OR a strong suspicion of TB based on sound clinical judgment. The most common symptom of pulmonary TB is productive cough for 2 weeks or more, which may be accompanied by other respiratory symptoms 
like: shortness of breath, chest pain, coughing up blood (haemoptysis). There may be other constitutional symptoms such as; loss of appetite, fever, weight loss, night sweats, tiredness [5] [6] [12] [13].

Concerning current TB diagnosis, WHO has recently issued policy recommendations on the use of the urine lateral flow lipoarabinomannan (LF-LAM) assay (AlereDetermine TM TB LAM Ag test) [14] [15]. The test is not recommended for TB screening or diagnosis of TB in most population groups. However, it is recommended to help with the diagnosis of TB in two population groups: HIV-positive people who are inpatient with signs or symptoms of TB and who have a CD4 cell countless than or equal to 100 cells $\mu \mathrm{L}$, and HIV-positive people who are "seriously ill" (both inpatients and outpatients) with danger signs, regardless of CD4 count or if the CD4 count is unknown. The use of the rapid molecular test Xpert MTB/RIF continues to expand in line with WHO recommendations for its use since December 2010. By the end of 2014, 69\% of countries reported that national policy by the end of 2014 indicated the use of Xpert MTB/RIF as the initial diagnostic test for people at risk of drug-resistant TB, and $60 \%$ reported that national policy indicated its use as the initial diagnostic test for people living with HIV. In 116 of the 145 countries eligible for concessional pricing that have purchased the technology, a total of 3763 GeneXpert machines had been procured for use in the public sector by the end of 2014. In 2014 alone, 4.8 million Xpert MTB/RIF test cartridges were procured, up from 550,000 in 2011.

Effective TB treatment has been shown to have a significant effect on the control of TB. Completion of treatment of active cases is therefore the most important priority of TB programs [12]. Effective treatment is achieved through Directly Observed Therapy-Short course (DOTS), a strategy developed by WHO in the 1990'swith main drugs for TB treatment comprising rifampicin, isoniazid, ethambutol, and pyrazinamide. Since the launch of DOTS, a total of 56 million people had been treated for TB between 1995 and 2012 [13]. In Nigeria as at the end of 2013, there were over 5000 TB service points and 1314 microscopic centers distributed across the entire country. Equally there are various capacities for diagnosis and treatment of multidrug resistance tuberculosis with two national and 6 zonal reference laboratories [14]. WHO reported that infection with HIV is the main reason for failure to meet Tuberculosis control targets in regions with high HIV prevalence [15]. Foremost challenges in TB treatment are; non-adherence to treatment, treatment default, and the emergence of resistance to drugs and particularly to multidrug resistant tuberculosis. These pose obstacles to effective TB control at both national and global levels. Resistance arises at various levels in the management of the patient, ranging from poor compliance, inadequate supervision, inadequate dosing, drug combinations, duration of treatment and poor staffing [16].

Treatment outcome of TB varies greatly even within close localities or treatment facilities. In Nigeria, the overall treatment success rate was $79 \%$ in 2002 , this increased to $85 \%$ in 2003 and then decreased to $83 \%$ in 2009. The default rate remained as high as $11 \%$ in the seven year period, while the death rate was as high as $6.7 \%$ [17] [18]. In a study in a tertiary hospital in Nnewi, Nigeria, $61.3 \%$ of the TB patients had successful treatment, $14.6 \%$ defaulted while $16.2 \%$ died [19]. In another study in private and public hospitals in Nnewi, Nigeria, the success rate was $57.3 \%$, default rate was $28.2 \%$ while $4.1 \%$ of the TB patients' died [20]. In Ilorin, a north central State of Nigeria, a $43.7 \%$ cure rate and $44.2 \%$ default rates were found over a 9 year review of records of TB cases [21]. A similar study in Ile-Ife, a south-western town in Nigeria, result showed that $73 \%$ of patients completed treatment while $27 \%$ defaulted at the some point [22]. In Ibadan, Nigeria $76.6 \%$ of the TB patients had their disease cured, $8.6 \%$ defaulted and $6.6 \%$ died [16]. In studies done in other countries of the world, various success rates were reported, it was $82.7 \%$ in a study from Addis Ababa, Ethiopia [23], 66\% in a study conducted in Thailand [24], 74.4\% reported from Limpopo south province Africa [25], 83.4\% reported in a teaching hospital in South India [26] and 92.6\% reported from a single center experience in Turkey [27]. Several factors have been reported in previous studies to influence the treatment outcome of tuberculosis. Socio demographic factors reported in previous studies were age of patients [27]-[32], sex of patients [17] [23] [28] [29] [32]-[37], educational/literacy status of patients [7] [27] [38], marital status [39], residence of patients [39]-[42], and poor knowledge of Tuberculosis [17] [40]. Clinical factors found to influence outcome of TB treatment in most reviewed studies were; diagnostic category [25] [27] [28] [43], treatment category/drug regimen [7] [27] [28] [40] [42] [43], presence of co-morbidities [28], hospitalization [28], sputum smear positivity at 3 months of treatment [28] [37], pre-treatment sputum result status [32] [42] [43], delay in treatment 42, HIV status of TB patients [19] [39] [44]-[46], bilateral radiologic lesions and cavities [28] [43]. Other factors reported were those related to type of health facility and house patient lived in [25] [39]. Based on the fact that TB has a high mortality rate, despite effective cure, there is an urgent need to closely monitor treatment as outlined by the DOTS strategy. Thus the aim of this study is to access the pattern of TB treatment outcome and factors influencing outcome among TB patients that received care in selected hospitals in Imo state, Nigeria. 


\section{Methodology}

\subsection{Study Area and Population}

This study was conducted in Imo State, South east Nigeria. Imo state is one of the 36 states in Nigeria and comprised 3 senatorial zones and 27 Local Government Areas with its capital situated at Owerri. It has an estimated population of about 4.8 million and a population density that varies from $230-1400$ people per sq. $/ \mathrm{km}$. The main occupation of the inhabitants is farming, trading. Majority of them were of Igbo extraction and most of them were Christians of different denominations. There are several Hospitals in the state ranging from tertiary to secondary to Primary Health Centers but this study was carried out in the three hospitals in the state namely; Imo State University Teaching Hospital, Orlu (IMSUTH), State Specialist Hospital Umuguma, Owerri, and Holy Rosary Hospital, Emekuku. All the three hospitals provide free TB and HIV services through the help of the National Tuberculosis and Leprosy Control Program (NTBLCP) and other concerned Non-government organizations in charge TB and HIV care in the state. Study population comprised TB cases in the selected hospitals who received treatment within the four year study period (2009-2012 cohorts).

\subsection{Study Design}

This study was a retrospective hospital based study of the outcome and determinants of TB treatment among patients that assessed care in three selected hospital in Imo state, Nigeria, within a 4 year period, (January 2009December 2012).

\subsection{Selection Criteria}

We included all the patients with TB infection that assessed care in the chest clinics of the selected hospitals within the study period. Any TB case that did not have contact with chest clinics of the selected hospitals was not enrolled.

\subsection{Sample Size Determination and Sampling Technique}

Using the Kish formula $\left(\mathrm{n}=\mathrm{Z}^{2} \mathrm{pq} / \mathrm{d}^{2}\right)$ [47] for determining adequate sample size and further correcting for population less than 10,000, using $\mathrm{n}_{1}=\mathrm{N} / 1+\left(\mathrm{N} / \mathrm{n}_{1}\right)$, a total of 1025 TB patients were studied.

Where $\mathrm{n}_{1}=$ corrected minimum sample size required, $\mathrm{Z}=$ standard normal deviate set at $1.96, \mathrm{p}=$ proportion of TB patients in previous study with successful treatment outcome (61.3\%) [19], $\mathrm{d}=$ level of precision set at $0.05, \mathrm{q}=1-\mathrm{p}, \mathrm{N}=$ estimate total number of TB cases in the state. The hospitals that were studied was purposively selected based on the patient load, availability of free TB and HIV services, presence of a chest clinic and availability of manpower for the clinics. Nevertheless total sampling was done, thus we studied all the 1025 TB patients that presented at the chest clinics of the hospitals within the study period whose documentations were complete.

\subsection{Data Collection}

Data on patients were collected using structured proforma. Data information was retrieved using TB case registers, personal folders and treatment cards of the patients. The proforma comprised three sections; section A: comprised information on sociodemographic characteristics, sections B: comprised information of clinical manifestations and laboratory test done while section c: comprised information on diagnosis, treatment received, and outcome of treatment. A diagnosis of tuberculosis was made either alone or by using a combination of the following; presence of symptoms suggestive of TB, abnormal chest radiograph, identification of acid-fast bacilli in sputum, gastric or body fluid, positive Mantoux test $>5 \mathrm{~mm}$ diameter and histology where necessary. Gene Xpert machine was only supplied to the institutions in 2013 and so was not used in the diagnosis of cases studied. Also as at the time of study, TB was classified as category1treatment (comprising rifampicin, isoniazid, ethambutol, and pyrazinamide) and category 11 (comprising streptomycin injection, rifampicin, isoniazid, ethambutol, and pyrazinamide) in combined or loose forms in accordance with WHO treatment recommendations. The standard anti-TB regimen adopted in the state hospitals is the DOTS regimen, which is used by the country's NTBLCP and recommended by WHO and International Union against Tuberculosis and Lung Disease (IUATLD) [14]. 


\subsection{Data Analysis}

The structured proforma was coded before entering the data into the computer and all the data were organized and analyzed by the researchers using a computer software, (EPI-INFO, version 7:1.3). Descriptive statistics were presented as frequencies, percentages, mean and standard deviation. For relationship of variables, chisquare was used and the p-value was set at 0.05 significant level.

\subsection{Ethnical Approval}

Approval was gotten from the Ethics and Research committee of the Department of Community Medicine Imo State University, Owerri and the management of the hospitals before proceeding for the study. Also oral permissions were gotten from the heads of the chest clinics and records departments of the hospitals.

\section{Result}

The mean age of the patients studied was $39.8 \pm 14.9$ years, with highest frequency occurring among the 31 - 45 years age bracket, $(44.7 \%)$, while the least frequency was among the 0 -15years age bracket, $(3.3 \%)$. There were more males, (53.6\%) than females, (46.4\%), with majority of them being currently married, $(60.8 \%)$ had secondary education, (61.4\%) and were employed, (63.8\%). There were more Catholics, (47.3\%) than other religious denomination and most of them, (83.4\%) reside in the rural areas of the state. A greater proportion of them were living with children less than five years of age, (53.8\%) and other adults in their apartments, (79.0\%) (Table 1).

Majority of the cases had sputum AAFB positive results, (86.3\%) at initial diagnosis with sputum conversion rate of $97.8 \%$ and $98.3 \%$ at 2 and 5 months of sputum AAFB examinations respectively. At 7 months a sizeable proportion of the TB patient (41.6\%) did not do their final sputum AAFB and majority of the TB diagnosis was made with a combination of laboratory results; positive Chest $\mathrm{x}$ ray + Sputum AAFB + Tuberculin test, (39.0\%) and Chest $\mathrm{x}$-ray and sputum AAFB positive results, (36.4\%).Nearly half of the patients (49.9\%) were found to be HIV positive with slightly above half, (51.0\%) of the HIV positive cases being on Highly Active Anti-retroviral Therapy (HAART) during TB treatment (Table 2).

The common symptoms at presentation were; cough greater than 2 weeks, $(96.7 \%)$, night sweats, $(85.0 \%)$ weight loss, (82.9\%) and loss of appetite, (72.2\%). Majority of the patients, (68.7\%) had contact with someone with history of chronic cough or confirmed TB. Most of the TB patients reviewed had pulmonary TB, (96.7\%) and majority of them (79.7\%) were new cases though treatment after default (10.2\%) was sizable. Most of the patients $(85.8 \%$ ) were treated with category 1 drugs and total success rate was $81.4 \%$ (cured, $46.3 \%$ and completed treatment, 35.1\%) although the default rate (9.8\%) was relatively high (Table 3).

Age of the patients were found to significantly influence treatment outcome $\left(\mathrm{X}_{\text {trend }}^{2}=6.289, \mathrm{df}=6, p<0.01\right)$ with highest success rate seen among those, 31-45 years age bracket, (83.2\%) and least success rate, among those within 0 - 15 years of age, (76.5\%) while default was commoner among the $0-15$ age bracket,(14.7\%). Sex of patient was significantly associated with treatment outcome of tuberculosis, $\left(\mathrm{X}_{\text {trend }}^{2}=71.301 \mathrm{df}=3, p<\right.$ 0.0001). Females had higher success rate, $(92.4 \%)$ while males had higher default rate, $(16.0 \%)$ deaths, $(10.4 \%)$ and failure rates, $(1.8 \%)$ respectively. Level of education attained by patient was found to significantly affect the outcome of TB treatment, $\left(\mathrm{X}_{\text {trend }}^{2}=4.364, \mathrm{df}=4, p<0.05\right)$. Success rate was highest among those with tertiary education, (88.0\%), default rate was higher among those with secondary education, (13.0\%), while death rate was higher among those with primary education (14.0\%). Religious denomination attended by patients was found to be significantly associated with TB treatment outcome, $\left(\mathrm{X}_{\text {trend }}^{2}=5.69, \mathrm{df}=4, p<0.05\right)$. The highest success rate was recorded among those in Pentecostal denomination, (93.6\%), while the lowest was recorded among Muslims, (66.7\%). Higher default rates, deaths and failure rates were recorded among Catholics, (14.6\%), Muslims, (33.3\%) and orthodox, (2.4\%) denominations respectively. Success rate was higher among the unemployed, (88.1\%) than employed, (77.5\%) while the default rate, (11.2\%) deaths, (9.5\%) and failure rates (1.8\%) were all higher among the employed patients, this variation in treatment outcome was statistically significant, $\left(X_{\text {trend }}^{2}=23.764, \mathrm{df}=2, p<0.0001\right)$. Also those living with under-five children, (88.9\%) had higher success rates than their counter parts living with none, $\left(\mathrm{X}_{\text {trend }}^{2}=4.686, \mathrm{df}=3, p<0.05\right)$, this was still the pattern with these living with other adults in their apartments, $(83.1 \%),\left(\mathrm{X}_{\text {trend }}=7.457, \mathrm{df}=3 p<0.01\right)$. Default rates were higher in those living without any under-five child, (13.3\%), nor adults (15.8\%). Marital status and residence of 
Table 1. Socio-demographic characteristics of Tuberculosis patients.

\begin{tabular}{|c|c|c|}
\hline Socio-demographic characteristics & Frequency $(n=1025)$ & Percentage \\
\hline \multicolumn{3}{|l|}{ Age group (yrs) } \\
\hline $0-15$ & 34 & 3.3 \\
\hline $16-30$ & 233 & 22.7 \\
\hline $31-45$ & 458 & 44.7 \\
\hline $46-60$ & 177 & 17.3 \\
\hline$>60$ & 123 & 12.0 \\
\hline Total & 1025 & 100.0 \\
\hline \multicolumn{3}{|l|}{ Sex } \\
\hline Male & 549 & 53.6 \\
\hline Female & 476 & 46.4 \\
\hline Total & 1025 & 100.0 \\
\hline \multicolumn{3}{|l|}{ Marital status } \\
\hline Currently married & 623 & 60.8 \\
\hline Never married & 285 & 27.8 \\
\hline Previously married & 117 & 11.4 \\
\hline Total & 1025 & 100.0 \\
\hline \multicolumn{3}{|l|}{ Educational status } \\
\hline None & 37 & 3.6 \\
\hline Primary & 93 & 9.1 \\
\hline Secondary & 629 & 61.4 \\
\hline Tertiary & 266 & 25.9 \\
\hline Total & 1025 & 100.0 \\
\hline \multicolumn{3}{|l|}{ Religion } \\
\hline Catholic & 485 & 47.3 \\
\hline Orthodox & 285 & 27.8 \\
\hline Pentecostal & 249 & 24.3 \\
\hline Muslim & 6 & 0.6 \\
\hline Total & 1025 & 100.0 \\
\hline \multicolumn{3}{|l|}{ Employment status } \\
\hline Employed & 654 & 63.8 \\
\hline Unemployed & 371 & 36.2 \\
\hline Total & 1025 & 100.0 \\
\hline \multicolumn{3}{|l|}{ Residence } \\
\hline Urban & 170 & 16.6 \\
\hline Rural & 855 & 83.4 \\
\hline Total & 1025 & 100.0 \\
\hline \multicolumn{3}{|l|}{ Living with under five children } \\
\hline Yes & 551 & 53.8 \\
\hline No & 471 & 46.8 \\
\hline Total & 1025 & 100.0 \\
\hline \multicolumn{3}{|l|}{ Living with other adults } \\
\hline Yes & 810 & 79.0 \\
\hline No & 215 & 21.0 \\
\hline Total & 1025 & 100 \\
\hline
\end{tabular}


Table 2. Pattern of sputum AAFB result, other laboratory results and HIV status of patients.

\begin{tabular}{|c|c|c|}
\hline Variable & Frequency & Percentage \\
\hline \multicolumn{3}{|l|}{ Initial sputum AAFB $(n=1025)$} \\
\hline Positive & 885 & 86.3 \\
\hline Negative & 140 & 13.3 \\
\hline Total & 1025 & 100.0 \\
\hline \multicolumn{3}{|c|}{ Sputum AAFB at 2months after treatment $(n=885)$} \\
\hline Positive & 17 & 1.7 \\
\hline Negative & 1008 & 98.3 \\
\hline Total & 1025 & 100.0 \\
\hline \multicolumn{3}{|c|}{ Sputum AAFB at 5months after treatment $(n=1025)$} \\
\hline Positive & 15 & 1.5 \\
\hline Negative & 983 & 95.9 \\
\hline Not done & 27 & 2.6 \\
\hline Total & 1025 & 100.0 \\
\hline \multicolumn{3}{|c|}{ Sputum AAFB at 7 months after treatment $(n=1025)$} \\
\hline Positive & 15 & 1.5 \\
\hline Negative & 583 & 56.9 \\
\hline Not done & 427 & 41.6 \\
\hline Total & 1025 & 100.0 \\
\hline \multicolumn{3}{|c|}{ Positive Lab results used for TB diagnosis $(n=1025)$} \\
\hline Chest X-ray only (CXR) & 51 & 5.0 \\
\hline Sputum AAFB only & 112 & 10.9 \\
\hline Tuberculin test only & 50 & 4.9 \\
\hline $\mathrm{CXR}+\mathrm{ESR}$ & 25 & 2.4 \\
\hline CXR + sputum AAFB + Tuberculin test & 400 & 39.0 \\
\hline $\mathrm{CXR}+$ sputum AAFB & 373 & 36.4 \\
\hline CXR + Tuberculin test & 14 & 1.4 \\
\hline Total & 1025 & 100 \\
\hline \multicolumn{3}{|l|}{ HIV status of TB patients $(n=1025)$} \\
\hline Positive & 511 & 49.9 \\
\hline Negative & 401 & 39.1 \\
\hline Unknown & 113 & 11.0 \\
\hline Total & 1025 & 100.0 \\
\hline \multicolumn{3}{|l|}{ HIV positive on HAART $(n=511)$} \\
\hline Yes & 261 & 51.0 \\
\hline No & 250 & 49.0 \\
\hline Total & 511 & 100.0 \\
\hline
\end{tabular}


Table 3. Pattern of clinical manifestations and treatment outcome of TB patients.

\begin{tabular}{|c|c|c|}
\hline Variable & Frequency $(n=1025)$ & Percentage \\
\hline \multicolumn{3}{|l|}{ Common clinical presentations ${ }^{* *}$} \\
\hline Cough & 991 & 96.7 \\
\hline Night sweats & 871 & 85.0 \\
\hline Weight loss & 850 & 82.9 \\
\hline Anorexia & 740 & 72.2 \\
\hline Fatigue & 661 & 64.5 \\
\hline Chest pain & 606 & 59.1 \\
\hline Hemoptysis & 551 & 53.8 \\
\hline Low grade fever & 450 & 43.9 \\
\hline \multicolumn{3}{|c|}{ History of contact with someone having chronic cough/TB } \\
\hline Yes & 704 & 68.7 \\
\hline No & 321 & 31.3 \\
\hline Total & 1025 & 100.0 \\
\hline \multicolumn{3}{|l|}{ Type of TB } \\
\hline Pulmonary TB & 994 & 97.0 \\
\hline Extra pulmonary TB & 31 & 3.0 \\
\hline Total & 1025 & 100.0 \\
\hline \multicolumn{3}{|l|}{ Type of patient at diagnosis } \\
\hline New & 817 & 79.7 \\
\hline Treatment after default/treatment after failure (TAF) & 105 & 10.2 \\
\hline Relapse & 37 & 3.6 \\
\hline Transferred in & 55 & 5.4 \\
\hline Others & 11 & 1.1 \\
\hline Total & 1025 & 100.0 \\
\hline \multicolumn{3}{|l|}{ Treatment category } \\
\hline Category 1 & 879 & 85.8 \\
\hline Category 11 & 146 & 14.2 \\
\hline Total & 1025 & 100.0 \\
\hline \multicolumn{3}{|l|}{ Treatment outcome } \\
\hline Cured & 475 & 46.3 \\
\hline Completed treatment & 359 & 35.0 \\
\hline Defaulted & 100 & 9.8 \\
\hline Died & 67 & 6.5 \\
\hline Failed treatment & 15 & 1.5 \\
\hline Transferred out & 9 & 0.9 \\
\hline Total & 1025 & 100.0 \\
\hline
\end{tabular}

\footnotetext{
${ }^{* *}=$ Multiple response.
} 
patients had no significant associations with TB treatment outcome, $p>0.05$ even though slight differences exist (Table 4).

Treatment category of TB patients was found to be significantly associated with treatment outcomes, $\left(\mathrm{X}_{\text {trend }}^{2}=\right.$ 194.617, $\mathrm{df}=3, p<0.0001$ ) with those that had category I treatment regimen having a higher success rates (88.2\%) than their counterparts that had category II (40.4\%), while default rates, (21.9\%) deaths, (32.2\%) and failure rates, (5.5\%) where higher among those that had category II regimens. Those with HIV negative or unknown results had 100\% success rates while those with HIV positive results had lower success rate, (62.6\%). All other poor treatment outcomes occurred among the HIV positive clients. This finding was statistically significant, $\left(\mathrm{X}_{\text {trend }}^{2}=233.662, \mathrm{df}=1\right.$, F.E. $\left.\mathrm{p}-<0.0001\right)$. There was no statistically significant difference in treatment outcome of TB between those that were on antiretroviral (ART) drugs (ART) and those that were not on drugs, $(p>0.05)$, even though more deaths occurred among those that were not on drugs, (22.0\%) while more defaults cases were seen among those that were on ART, (29.9\%).Type of patient at presentation was found to significantly influence the outcome of TB treatment, $\left(\mathrm{X}_{\text {trend }}^{2}=68.854, \mathrm{df}=6, p<0.0001\right)$, with new cases at presentation having the highest success rate (85.8\%) and relapse having the least success rate (29.8\%) while more deaths, (37.8\%) and failure rates, (21.6\%) were recorded among the relapse cases (Table 5).

\section{Discussion}

The mean age of the patients was $39.8+14.9$ years with majority of them (84.7\%) being within the economically productive age group, 15 - 60 years. Several studies have reported similar pattern especially in developing countries [7] [17] [19] [20] [22] [48] [49]. It has been postulated that due to their age factor and family economy depending on them, they involve themselves in earning and get exposed to other cases in the community [26]. This pattern was contrary to what was reported in developed countries where finding suggest the elderly group to be two to four time more prevalent [50]. The burden of TB in this study was more among males (53.6\%), than the females (46.4\%). Similar pattern have been reported in several studies [7] [17] [19]-[21] [26] [32] [36] [49] [51]. WHO global TB report 2015, showed that male to female ration of notified cases across all age groups was 1.7, globally ranging from 1.0 in the Eastern Mediterranean Region to 2.1 in the West Pacific Region [9]. This difference could likely be associated to risk of exposure to the bacilli which is, mostly airborne. Nevertheless Getahun et al., (2013) reported higher TB Burden among females than males in Addis Ababa Ethiopia [23].

Majority of the patients reviewed (96.7\%) had pulmonary TB with most of them (79.7\%) being new cases. This report was in line with findings from some of the reviewed works [5] [6] [19] [29] [52]. It has been globally reported that TB occurs mostly as pulmonary types in greater than $80 \%$ of all cases [5] [6]. Yet some other studies reported lower proportions of pulmonary TB when compared to ours; $64.6 \%$ in India by Chennaveerappa et al., [26] and 59.5\% by Getahun et al., in Ethiopia. Also majority of the all TB cases (86.3\%) were sputum AAFB positive at initial sputum test done, with sputum conversion rates of $97.8 \%$ and $98.3 \%$ respectively at the $2^{\text {nd }}$ and $5^{\text {th }}$ months of sputum examination. High sputum smear positive results as seen in our study have be reported in previous studies [44] [51]. However our finding of high smear positive cases was higher than what was reported in Nnewi, Eastern Nigeria by Adinma et al., (44.1\%), Oshogbo, South west Nigeria by Egbewale et al., $(67.0 \%)$ [52] and even a much lower rate (0.8\%) has been reported in a study from Ethiopia [23]. Also to note is that smear positive sero-conversion rates as high as what was seen in our study has been reported elsewhere [52]. The TB/HIV confection found in this study was $49.9 \%$ with slightly above half of the HIV positive TB cases (51.0\%) being on antiretroviral drugs. This finding was higher than the national prevalence of HIV among TB patients which increased from 2.2\% in 1991 to $19.1 \%$ in 2001 and 25\% in 2010 [18]. Also to note is that only 33\% of TB/HIV co-infected cases in Nigeria were on antiretroviral therapy when compared to higher proportion of $50.1 \%$ found in our study 18]. The co-infection rates vary greatly among the reviewed works, while some where reporting lower figures [6] [19] [39], others reported figures within the same limits as ours or even higher [51] [53] [54]. HIV pandemic has fueled an unprecedented increase in TB primarily because of its effect in the immune system of infected individuals.

The treatment outcomes of TB treatment in this study showed a total success rate of $81.4 \%$ (cure, $46.3 \%$ and completed treatment, 35.1\%), default rate, (9.8\%), died, (6.5\%), failed, (1.5\%) and transferred out (0.9\%). This treatment success recorded in this study was slightly lower than $86 \%$ reported both nationally and globally among the 2013 TB treatment cohort [9]. It was also lower than figures reported from studies in Ekiti state Nigeria, (93.0\%) [55], Turkey (94.7\%) [43], India, (84.6\%) [7] and also below the national recommended target of 
Table 4. Association between socio-demographic characteristics of patients and treatment outcome of tuberculosis.

\begin{tabular}{|c|c|c|c|c|c|c|}
\hline \multirow{2}{*}{ Variable } & \multicolumn{5}{|c|}{ Treatment outcome of tuberculosis } & \multirow{2}{*}{$\begin{array}{c}\text { Statistics } \\
\left(\chi^{2}\right) / p \text {-value }\end{array}$} \\
\hline & Successful Rx (\%) & Uncertain Outcome (\%) & Died (\%) & Failed Rx (\%) & Total (\%) & \\
\hline \multicolumn{7}{|l|}{ Age group (yrs) } \\
\hline $0-15$ & $26(76.5)$ & $5(14.7)$ & $3(8.8)$ & $0(0.0)$ & $34(100)$ & \\
\hline $16-30$ & $186(79.8)$ & $32(13.8)$ & $14(6.0)$ & $1(1.4)$ & $233(100)$ & 6.289 \\
\hline $31-45$ & $381(83.2)$ & $51(11.1)$ & $24(5.2)$ & $2(0.5)$ & $458(100)$ & $\mathrm{df}=6$ \\
\hline $46-60$ & $146(82.5)$ & $11(6.2)$ & $13(7.3)$ & $7(4.0)$ & $177(100)$ & $p=0.012^{*}$ \\
\hline$>60$ & $95(77.2)$ & $10(8.1)$ & $13(10.6)$ & $5(4.1)$ & $123(100)$ & \\
\hline Total & $834(81.4)$ & $109(10.6)$ & $67(6.5)$ & $15(1.5)$ & $1025(100)$ & \\
\hline \multicolumn{7}{|l|}{ Sex } \\
\hline Male & $394(71.8)$ & $88(16.0)$ & $57(10.4)$ & $10(1.8)$ & $549(100)$ & 71.301 \\
\hline Female & $440(92.4)$ & $21(4.4)$ & $10(2.1)$ & $5(1.1)$ & $476(100)$ & $\mathrm{df}=3$ \\
\hline Total & $834(81.4)$ & $109(10.6)$ & 67 (6.5) & $15(1.5)$ & $1025(100)$ & $p=0.000^{*}$ \\
\hline \multicolumn{7}{|l|}{ Marital status } \\
\hline Currently married & $504(81.0)$ & $65(10.4)$ & $40(6.4)$ & $14(2.2)$ & $623(100)$ & 1.170 \\
\hline Never married & $228(80.0)$ & 33 (11.6) & $23(8.1)$ & $1(0.3)$ & $285(100)$ & $\mathrm{df}=4$ \\
\hline Previously married & $102(87.2)$ & $11(9.4)$ & $4(3.4)$ & $0(0.0)$ & $117(100)$ & $p=0.281$ \\
\hline Total & $834(81.4)$ & $109(10.6)$ & $67(6.5)$ & $15(1.5)$ & $1025(100)$ & \\
\hline \multicolumn{7}{|l|}{ Educational status } \\
\hline None & $32(86.5)$ & $4(10.8)$ & $1(2.7)$ & $0(0.0)$ & 37 (100) & 4.364 \\
\hline Primary & $71(76.3)$ & $8(8.6)$ & $13(14.0)$ & $1(1.1)$ & $93(100)$ & $\mathrm{df}=4$ \\
\hline Secondary & $497(79.0)$ & $82(13.0)$ & $45(7.2)$ & $5(0.8)$ & $629(100)$ & $p=0.037^{*}$ \\
\hline Tertiary & $234(88.0)$ & $15(5.6)$ & $8(3.0)$ & $9(3.4)$ & $266(100)$ & \\
\hline Total & $834(81.4)$ & $109(10.6)$ & $67(6.5)$ & $15(1.5)$ & $1025(100)$ & \\
\hline \multicolumn{7}{|l|}{ Religion } \\
\hline Catholic & $374(77.2)$ & $71(14.6)$ & $35(7.2)$ & $5(1.0)$ & $485(100)$ & 5.069 \\
\hline Orthodox & 233 (81.8) & $24(8.4)$ & $21(7.4)$ & $7(2.4)$ & $285(100)$ & $\mathrm{df}=4$ \\
\hline Pentecostal & 223 (93.6) & $14(5.6)$ & $9(3.6)$ & $3(1.2)$ & $249(100)$ & $p=0.024^{*}$ \\
\hline Muslim & $4(66.7)$ & $0(0.0)$ & $2(33.3)$ & $0(0.0)$ & $6(100)$ & \\
\hline Total & $834(81.4)$ & $109(10.6)$ & $67(6.5)$ & $15(1.5)$ & $1025(100)$ & \\
\hline \multicolumn{7}{|l|}{ Employment status } \\
\hline Employed & $507(77.5)$ & $73(11.2)$ & $62(9.5)$ & $12(1.8)$ & $654(100)$ & 23.764 \\
\hline Not employed & $327(88.1)$ & $36(9.7)$ & $5(1.4)$ & $3(0.8)$ & $371(100)$ & $\mathrm{df}=2$ \\
\hline Total & 834 (81.4) & $109(10.6)$ & 67 (6.5) & $15(1.5)$ & $1025(100)$ & $p=0.000^{*}$ \\
\hline \multicolumn{7}{|l|}{ Residence } \\
\hline Urban & $138(81.2)$ & $26(15.2)$ & $3(1.8)$ & $3(1.8)$ & $170(100)$ & 0.001 \\
\hline
\end{tabular}




\section{Continued}

$\begin{array}{lcccccc}\text { Rural } & 696(81.5) & 83(9.7) & 64(7.4) & 12(1.4) & 855(100) & \mathrm{df}=2 \\ \text { Total } & \mathbf{8 3 4 ( 8 1 . 4 )} & \mathbf{1 0 9 ( 1 0 . 6 )} & \mathbf{6 7 ( 6 . 5 )} & \mathbf{1 5 ( 1 . 5 )} & \mathbf{1 0 2 5}(\mathbf{1 0 0}) & p=0.980\end{array}$

Living with children under 5 years of age

$\begin{array}{ccccccc}\text { Yes } & 462(83.9) & 46(8.3) & 37(6.7) & 6(1.1) & 551(100) & 4.686 \\ \text { No } & 372(78.5) & 63(13.3) & 30(6.3) & 9(1.9) & 474(100) & \mathrm{df}=3 \\ \text { Total } & \mathbf{8 3 4 ( 8 1 . 4 )} & \mathbf{1 0 9 ( \mathbf { 1 0 . 6 } )} & \mathbf{6 7}(\mathbf{6 . 5}) & \mathbf{1 5 ( 1 . 5 )} & \mathbf{1 0 2 5}(\mathbf{1 0 0 )} & P=0.030^{*}\end{array}$

Living with adults

$\begin{array}{lrrrrrr}\text { Yes } & 673(83.1) & 75(9.3) & 53(6.5) & 9(1.1) & 810(100) & 7.457 \\ \text { No } & 161(74.9) & 34(15.8) & 14(6.5) & 6(2.8) & 215(100) & \mathrm{df}=3 \\ \text { Total } & \mathbf{8 3 4 ( 8 1 . 4 )} & \mathbf{1 0 9 ( 1 0 . 6 )} & \mathbf{6 7 ( 6 . 5 )} & \mathbf{1 5 ( 1 . 5 )} & \mathbf{1 0 2 5 ( \mathbf { 1 0 0 } )} & p=0.006^{*}\end{array}$

Successful $\mathrm{Rx}=$ cured and completed treatment, uncertain outcome = defaulted and transferred out, ${ }^{*}=$ significant

Table 5. Association between clinical Status of patient and treatment outcome of tuberculosis.

\begin{tabular}{|c|c|c|c|c|c|c|}
\hline \multirow{2}{*}{ Variable } & \multicolumn{5}{|c|}{ Treatment outcome of tuberculosis } & \multirow{2}{*}{$\begin{array}{c}\text { Statistics } \\
\left(\chi^{2}\right) / \mathbf{p} \text {-value }\end{array}$} \\
\hline & Successful Rx (\%) & Uncertain Outcome (\%) & Died (\%) & Failed Rx (\%) & Total (\%) & \\
\hline \multicolumn{7}{|c|}{ Treatment category } \\
\hline Category 1 & $775(88.2)$ & 77 (8.7) & $20(2.3)$ & $7(0.8)$ & $879(100)$ & 194.617 \\
\hline Category 11 & $59(40.4)$ & $32(21.9)$ & $47(32.2)$ & $8(5.5)$ & $146(100)$ & $\mathrm{df}=3$ \\
\hline Total & $834(81.4)$ & $109(10.6)$ & $67(6.5)$ & $15(1.5)$ & $1025(100)$ & $p=0.000^{*}$ \\
\hline \multicolumn{7}{|c|}{ HIV status of patient } \\
\hline Positive & $320(62.6)$ & $109(21.3)$ & $67(100)$ & $15(3.0)$ & $511(100)$ & 233.662 \\
\hline Negative & $401(100)$ & $0(0.0)$ & $0(0.0)$ & $0(0.0)$ & $401(100)$ & $\mathrm{df}=1$ \\
\hline Not done & $113(100)$ & $0(0.0)$ & $0(0.0)$ & $0(0.0)$ & $113(100)$ & $\mathrm{F}=0.000^{*}$ \\
\hline Total & $832(81.4)$ & $109(10.6)$ & $67(6.5)$ & $15(1.5)$ & $1025(100)$ & \\
\hline \multicolumn{7}{|c|}{ HIV positive on drugs $(n=511)$} \\
\hline Yes & $165(63.2)$ & 78 (29.9) & $12(4.6)$ & $6(2.3)$ & $261(100)$ & 1.205 \\
\hline No & $155(62.0)$ & $31(12.4)$ & $55(22.0)$ & $9(3.6)$ & $250(100)$ & $\mathrm{df}=3$ \\
\hline Total & $320(62.6)$ & $109(21.3)$ & $67(13.1)$ & $15(3.0)$ & $511(100)$ & $p=0.273$ \\
\hline \multicolumn{7}{|c|}{ Type of patient at presentation } \\
\hline New cases & 701 (85.8) & 94 (11.5) & $20(2.5)$ & $2(0.2)$ & $817(100)$ & 68.854 \\
\hline $\mathrm{TAD} / \mathrm{TAF}$ & $68(64.8)$ & $5(4.8)$ & $29(27.6)$ & $4(3.8)$ & $105(100)$ & $\mathrm{df}=6$ \\
\hline Relapse & $11(29.8)$ & $4(10.8)$ & 14 (37.8) & 8 (21.6) & 37 (100) & $p=0.000^{*}$ \\
\hline Transfer in/others & $55(83.3)$ & $6(9.1)$ & $4(6.1)$ & $1(1.5)$ & $66(100)$ & \\
\hline Total & $834(81.4)$ & $109(10.6)$ & $67(6.5)$ & $15(6.5)$ & $1025(100)$ & \\
\hline
\end{tabular}

Successful Rx = cured and completed treatment, uncertain outcome = defaulted and transferred out, ${ }^{*}=$ significant, TAD = treatment after default, $\mathrm{TAF}=$ treatment after failure . 
85\% [14]. Nevertheless, the treatment success found in this study was higher than figures reported in studies from, Nnewi, (61.3\%) [19] Owo Ondo state, (75.5\%) [51] Ibadan (76.6\%) [17], Ebonyi state, (65.8\%) [40], Abuja, (65.8\%) [39] all from Nigeria and in Limpopo South Africa, (74.4\%) [25]. Yet our findings compares favorably with the treatment successes reported in some other studies; 82\% from a study in Enugu state [49], 80\% in another study from Ebonyi state [56], 83.4\% in India [26] and 82.7\% in Addis Ababa, Ethiopia [23]. This variations in treatment success is likely to have been caused by various socio-demographic/economic factors, issues related to drug compliance and monitoring, nutritional status of individuals, the HIV pandemic, and drug susceptibility/resistance among others which varies greatly from place to place. Default rates, death rates, and failure rates of $9.8 \%, 6.5 \%$, and $1.5 \%$ respectively were still within the national range [18]. It was also similar to what was obtained in Enugu state, Nigeria [49] and in a study from India [26]. This high default rate is of great concern due to its public health implication in spreading the disease and in the emergence of resistance strains of the TB organism. The reasons that could be responsible for this lower treatment outcome found in our study could be due to ignorance, poor compliance to drug treatment, long duration of drug intake, distance of home from health facility, improper health education, stigmatization, poor social support, lack of regular availability of drugs and other consumables, lack of political will, and the attitude of the health workers among others as has been reported in other studies [19] [51] [52] [55] [56].

Socio-demographic factors found to be associated significantly with TB treatment outcome were, age of patient, gender, educational status, religious denomination attended, employment status, living with under five children and living with an adult in the household. Other clinical/medical factors associated with TB treatment outcome significantly were; type of treatment category patient was on, HIV status of patient, and type of patient at diagnosis.

Concerning age of patients, lower successful outcomes were recorded in both extremes of age. Also death rates were high in both extremes of age. This pattern has been reported in a study from Turkey [28] which revealed that there was a significant positive trend of increased risk for adverse treatment outcomes with age, with almost two and three fold increase in odds of an adverse treatment outcome among patients aged 51 - 65 years and 65 years respectively. Other studies had shown significant association between death and older age [29]-[31] [43], and extremes of age with lower proportions of treatment success [23] [25]. Yet several other studies showed no association between age and treatment outcome of TB [19] [39] [41] [42] [52]. This association with extremes of age may partly be explained by the effect of co-morbidity confounders common at the extremes of age that are likely to worsen the outcome of TB treatment. This argument was strengthened by the finding in a Turkish study which revealed that co-morbidity was associated with a near doubling of the odds for an adverse TB treatment outcome [28].

Gender showed that females had a higher treatment success (92.4\%) than their male counterparts, $(71.8 \%)$ while males had higher levels of poor treatment out comes than females. This pattern of lower success rates among males has been supported by several studies, [7] [17] [23] [29] [32]-[34] [37] [43] [57]. Nevertheless one of the studies reported a higher burden among female patients while some others reported no effect of gender on TB treatment outcome [19] [41] [42] [52]. Gender differences in tuberculosis epidemiology may arise either as a consequence of differences in biological functioning or due to differences in the societal roles of men and women. Thus despite facing obstacles such as stigma, negligence, poverty and low detection rate, better results were seen in females globally [7] [9].

Concerning educational status, those with Tertiary education had better success rates (88.0\%) than their other counterparts with lower educational status. Sengul et al., reported that high educational status was significantly associated with successful PTB treatment outcome [27]. Also, Kanugo et al. (2015) [38] and Sadana et al. (2015) [7] both reported that better treatment outcomes were seen among literate patients. Another study in Ibadan Nigeria reported that poor treatment outcome was associated with poor knowledge about TB. [17] Yet in some other studies, educational status of individuals did not play any significant role in TB treatment outcome [28] [39]. Generally, education increase knowledge which if positive will influence attitude and behavior which may help patients to comply with treatment and also practice proper preventive measures which might in turn improve the outcome of treatment.

Religious denomination attended by patients was found to significantly influence the outcome of TB treatment, with those in Pentecostal denominations having the highest success rate (93.6\%) while the leastwas found among the Muslims. This finding was contrary to that reported by Mukhopadhyay et al., (2010) which shows no difference in use between the Hindus, Muslims and Santhals in west Bengal, India. [43] Religious believes play vital role in shaping the behavior of its worshippers and so could influence outcome depending on their pattern 
of beliefs as pertains to health care seeking practices. Those who were not employed, (88.1\%) in our study had a better treatment outcome than their counter parts that were employed, (77.5\%). Sengul et al., (2015) [27] reported no association between TB treatment outcomes with occupation. Also Sadana et al., (2015) [7] reported no association between treatment outcome and socio economic status of TB patients. Most of those classified as unemployed in this study which were mainly students and housewives may have come from rich and educated families. Also because they're not working may have given them time to comply to the drug regimens thereby having better successful rates than their counterparts who may be busier and may forget to take their drugs. This could also be partly explained by the fact that most of them are dependents and could be easily be monitored by family members in taking their drugs thereby improving compliance and treatment success.

Those living with under-fives, (83.9\%) and those living with other adults, (83.1\%) in their household were more likely to have better treatment successes than their counterparts living alone. Sengul et al., [27] (2015) found no association between family size and successful treatment outcome of TB. Also Sadana et al., [7] (2015) reported no association between type of family and outcome of TB treatment. This positive finding in our study could be associated with high emphasis placed on informing and screening close contacts of PTB sputum positive patients especially the under-five children in our DOTS clinics. Also it is compulsory in our setting to bring close persons who could help them take their drugs and can also be contacted when need arises. Because of the influence of these close persons to them and the risk of infecting others, they are likely to comply in properly taking their drugs which will likely improve treatment outcome.

Patients on category 1 drug treatment had a higher treatment success, (88.2\%) than their counterparts on category II treatment regimen, (40.4\%) with those in category II having higher poor treatment outcome (59.6\%). This pattern was consistent with finding reported by Sadana et al., (2015) [7] and Mukhopadhyay et al., 2010 [42]. A study in Limpopo South Africa also reported a strong association between treatment regimen and outcome of TB treatment [25]. Also, some other studies showed a higher treatment outcome in those that had no drug resistant of any form [27] [43]. Patient category or type of patient at presentation was found to significantly affect the outcome of TB treatment with new cases at presentation having the highest success rate, (85.8\%) while relapse cases having the least success rate, (29.8\%). This pattern of high TB treatment success among new cases has been reported by several studies [25] [27] [28] [43]. Yet some others reported no significant effect on the treatment outcome by both the drug regimen used and the type of patient at diagnosis [19] [23] [41]. This report could likely be due to the fact that most category II patients are re-treatment cases and might have been long on the drugs leading to poor compliance to drugs, development of resistance to drugs and in turn poor treatment outcome.

Those that where HIV negative or with unsure status has a treatment success of $100 \%$ when compared to $62.6 \%$ among HIV positive cases. Globally treatment success was higher among HIV negatives (88\%) than positives (73\%) and this was still the pattern in Africa; (84\% versus 75\%) [9] [10]. This finding of lower success rates among HIV/TB co-infected patients is in tandem with findings in Nnewi, Anambra State [19], and Abuja, Nigeria [39] both conducted among patients in tertiary hospital settings. Nevertheless the success treatment outcome was not affected by the use of antiretroviral among the HIV positives though death rates were drastically reduced among those on ART and transfer out/defaults were more among those not receiving ART drugs. This pattern has been reported in previous studies [19] [41] while some others reported improved outcome with initiation of ART [41] [58]-[60]. HIV pandemic has fueled an unprecedented increase in TB owing to its effects on the immune system of individuals and in combination. This union has a lethal effect on individuals with co-infection. The reported reduction in deaths among TB/HIV co-infected cases on antiretroviral therapy in this study collaborates with WHO report that between 2000 and 2014, TB treatment and antiretroviral therapy saved an additional 18million lives among HIV positives people [9]. This result could have been affected by the fact that only about half of the respondents were on drugs with some of them being transferred out or defaulted as at the time this study was conducted. This is true in that only one third of HIV positive TB cases in Nigeria are assessing ART [41], leaving the rest to be without drugs thereby necessitating a high drop out of TB/HIV cases and possible poor treatment outcome.

Other socio demographic factors that did not significantly affect outcome of TB treatment were; marital status, place of residence. This pattern has been reported in some other studies [7] [17] [19] [42].

\section{Conclusion and Recommendations}

The success rate of $81.4 \%$ found in this study was still below the target of $85 \%$ rate set by WHO. Both the de- 
fault rate and death rate were still relatively high. If this status quo remains, it will be difficult to achieve the national and global target of reducing TB deaths by at least $50 \%$. Most of the associated factors can be modified to improve the status of TB treatment if adequate attention is given by the relevant authorities. There is a need to monitor patients closely for compliance to treatment and efforts should be made to screen patients on time for HIV. Also ART drugs should be made available and initiated on time as this will help to reduce adverse treatment outcomes. Continuous health education to the populace concerning TB, its treatment and prevention will go a long way to improve outcome of treatment generally, as education is key to positive behavioral and attitudinal change.

\section{Acknowledgements}

We want to thank all the TB patients who were studied, the hospital staff for their co-operation and the students who helped us in the collection of data.

\section{Author's Contribution}

All the authors contributed in different sections of this study.

\section{Conflicting Interest}

The authors hereby declare that there is no conflicting interest.

\section{Source Funding}

There was no external source of funding.

\section{References}

[1] Ofoegbu, O.S. and Odume, B.B. (2015) Treatment Outcome of Tuberculosis Patients at National Hospital Abuja, Nigeria: A Five Year Retrospective Study. South African Family Practice, 57, 50-56. http://dx.doi.org/10.1080/20786190.2014.995913

[2] Mahar, D., Borgdoff, M. and Boerma, T. (1999) HIV Related Tuberculosis: How Well Are We Doing with the Current Control Efforts? International Journal of Tuberculosis and Lung Disease, 9, 17-24.

[3] World Health Organization (WHO) (2010) Global Tuberculosis Control. WHO Report, Geneva, (WHO/HTM/TB/2010.7). http://www.who.int/tb/publications/global_report/achive/en/

[4] Getahun, H., Gunneberg, C., Granich, R., et al. (2010) HIV Infection-Association Tuberculosis; the Epidemiology and the Response. Clinical Infectious Diseases, 50, S201-S207. http://dx.doi.org/10.1086/651492

[5] Raviglione, M.O. and Brien, R. (2012) Harrison’s Principles of Internal Medicine. 18th Edition, McGraw-Hill Companies Inc., Boston.

[6] Duru, C.B, Uwakwe, K.A., Diwe, K.C., Nnebue, C.C., Chineke, H.N. and Emerole, C.A. (2014) Prevalence of Active Pulmonary Tuberculosis among HIV Positive Patients Attending Adult HIV Clinic in a Teaching Hospital in IMO State, South, East Nigeria: A 6 Year Review (2006-2012). Indian Journal of Medical Research and Pharmaceutical Sciences, 16, 10-20.

[7] Sadana, P., Singh, T. and Deepti, S.S. (2015) Socio-Demographic Factors Affecting the Treatment Outcome in Patients of Tuberculosis. National Journal of Community Medicine, 6, 609-613.

[8] World Health Organization (2014) Global Tuberculosis Report 2014. WHO, Geneva. (WHO/HTM/TB/2014.08). http://www.who.int/tb/publications/global_report/achive/en/

[9] WHO (2015) World Health Organization Global Tuberculosis Control. WHO, Geneva. http://www.who.int/tb/publications/global_report/en/

[10] Kanabus, A. (2016) Information about Tuberculosis: TB Statistics-Global, Regional and High Burden. Global Health Education (GHE). www.tbfacts.org

[11] World Health Organization (2016) Tuberculosis Media Centre Facts Sheet N ${ }^{\circ} 104$. WHO, Geneva. http://www.who.int/mediacenter/factsheets/fs104/en/

[12] Wobeser, W., Yuan, L. and Naus, M. (1999) The Tuberculosis Treatment Completion Study Group. Outcome of Pulmonary Tuberculosis Treatment in the Tertiary Care Setting-Toronto. CMA, 160, 789-794.

[13] World Health Organization (2013) Global TB Report 2012. WHO, Geneva. 
www.who.int/pubulication/factsheet-global.pdt

[14] Federal Ministry of health (FMoH) Abuja, Nigeria (2014) National Tuberculosis, Leprosy and Buruli ulcer Management and control Guidelines. 6th Edition, Department of public Health: National Tuberculosis and Leprosy Control Programme, 7.

[15] WHO (1997) World Health Organization Global Tuberculosis Control. (Refno: WHO/TB/97.2250). WHO, Geneva, 915.

[16] Park, K. (2007) Parks Textbook of Preventive and Social Medicine. 19th Edition, M/S Banarsidas Bhanot Publishers, Jabalpur, 798-806.

[17] Fatiregun, A.A., Ojo, A.S. and Bamgboye, A.E. (2009) Treatment Outcomes among Pulmonary Tuberculosis Patient at Treatment Centre in Ibadan, Nigeria. Annals of Africa Medicine, 8, 100-104. http://dx.doi.org/10.4103/1596-3519.56237

[18] United State Embassy in Nigeria (2012) Nigeria Tuberculosis Fact Sheet. Economic Section, United State Embassy in Nigeria, January. http://nigeria.usembassy.gov

[19] Adinma, E.D., Iloghalu, I.C., Azubuike, E.C., Obi, D.C., Mbanuzuru, N.A., Nwabueze, S.A. and Modebe, I.A. (2015) Outcome of Tuberculosis Treatment in Tertiary Hospital in South Eastern Nigeria. International Invention Journal of Medicine and Medical Sciences, 2, 17-22.

[20] Efegbere, H.A., Anyabolu, A.E., Onyeyili, A.N., Efegbere, E.K., Sani-Gwarzo, N., Omoniyi, A., et al. (2014) Detarminants of Treatment Outcome of Public-Private Mix Tuberculosis Control Programme in South Eastern Nigeria. Afrimedic Journal, 5, 25-37.

[21] Salami, A.K. and Oluboyo, P.O. (2003) Management Outcome of Pulmonary Tuberculosis: A Nine Year Review in Ilorin. West African Journal of Medicine, 22, 114-119.

[22] Erhabor, G.E., Adebayo, R.A., Omodara, J.A. and Famurewa, O.L. (2003) Ten Year Review of Patterns of Presentation and Outcome of Pulmonary Tuberculosis in OAUTHC, Ile-Ife, Nigeria. Journal of Health Science, 3, 34-39.

[23] Getahun, B., Ameni, G., Medlin, G. and Biadgilin, S. (2013) Treatment Outcome of Tuberculosis Patients under Directly Observed Treatment in Addis Ababa, Ethopia. Brazilian Journal of Infectious Diseases, 17, 521-528. http://dx.doi.org/10.1016/j.bjid.2012.12.010

[24] Anuwatnonthakate, A.L., Nateniyonn, S., Wattanaamornkiat, W., et al. (2008) Directly Observed Therapy and Improved Tuberculosis Treatment Outcomes in Thailand. PLoS ONE, 3, e3089. http://dx.doi.org/10.1371/journal.pone.0003089

[25] Gafar, M.M. (2013) Factors Affecting Treatment Outcomes in Tuberculosis (TB) Patients in the Limpopo Province, South Africa. Master's Thesis, University of Limpopo, Limpopo. http://hdl.handle.net/10386/1017

[26] Chennaveerappa, P.A., Siddharam, S.M., Halesha, B.R., Vittal, B.G. and Jayashree, N. (2011) Treatment Outcomes of Tuberculosis Patients Registered at DOTS Center in a Teaching Hospital, South India. International Journal of Biological and Medical Research, 2, 487-489.

[27] Sengul, A., Akturk, U.A., Aydemir, Y., Kaya, N., Kocak, N.D. and Tasolar, F.T. (2015) Factors Affecting Successful Treatment Outcomes in Pulmonary Tuberculosis: A Single-Center Experience in Turkey, 2005-2011. The Journal of Infection in Developing Countries, 29, 821-828. http://dx.doi.org/10.3855/jidc.5925

[28] Babalik, A., Kilicaslan, Z., Kizitas, S., Gencer, S. and Ongen, G. (2013) A Retrospective Case Control Study, Factors Affecting Treatment Outcomes for Pulmonary Tuberculosis in Istanbul, Turkey. Balkan Medical Journal, 30, $204-210$. http://dx.doi.org/10.5152/balkanmedj.2013.005

[29] Lefebvre, N. and Falzon, D. (2008) Risk Factors for Death among Tuberculosis Cases: Analysis of European Surveillance Data. European Respiratory Journal, 31, 1256-1260. http://dx.doi.org/10.1183/09031936.00131107

[30] Najera-ortiz, J.C., Sanchez-perez, H.J., Ochoa-Diaz, H., Arana-Cedeno, M., Lezama, M.S. and Mateo, M.M. (2008) Demographic, Health Service and Socio Economic Factors Associated with Pulmonary Tuberculosis Mortality in Los Altos Region of Chiapas, Mexico. International Journal of Epidemiology, 37, 786-795. http://dx.doi.org/10.1093/ije/dyn089

[31] Baussano, I., Pivetta, E., Abbona, F. and Bugiani, M. (2008) Predicting Tuberculosis Treatment Outcomes in a LowIncidence Area. International Journal of Tuberculosis and Lung Disease, 12, 1441-1448.

[32] Tessema, B., Muche, A., Bekele, A., Reissig, D., Emmrich, F. and Sack, U. (2009) Treatment Outcome of Tuberculosis Patients at Gondar University Teaching Hospital, Northwest Ethiopia: A Five Year Retrospective Study. BMC Public Health, 9, 371. http://dx.doi.org/10.1186/1471-2458-9-371

[33] Ahmad, S.R. and Velhal, G.D. (2013) Study of Treatment Outcome of New Sputum Smear Positive TB Cases under Dots-Strategy. International Journal of Pharma and Bio Sciences, 4, 1215-1222.

[34] Makherjee, A., Saha, T., Sarkar, A. and Chowdhurry, R. (2012) Gender Differences in Notification Rates, Clinical 
Forms and Treatment Outcome of Tuberculosis Patients under the RNTCP. Lung India, 29, 120-122. http://dx.doi.org/10.4103/0970-2113.95302

[35] Lienhardt, C., Manneh, K., Bon Chier, V., Lahai, G., Milligan, P.J. and McAdam, K.P. (1998) Factors Determining the Outcome of Treatment of Adult Smear Positive Tuberculosis Cases in Gambia. The International Journal of Tuberculosis and Lung Disease, 2, 712-718.

[36] Diel, R. and Nieman, S. (2003) Outcome of Tuberculosis Treatment in Harmburg: A Survey, 1997-2001. The International Journal of Tuberculosis and Lung Disease, 7, 124-131.

[37] Dooley, K.E., Lahlou, O., Ghali, I., Knudsen, J., Elmessaoudi, M.D., Cherkaoui, I. and Aouadi, R.E. (2011) Risk Factors for Tuberculosis Failure, Default, or Relapse and Outcomes of Retreatment in Morocco. BMC Public Health, 11, 140. http://dx.doi.org/10.1186/1471-2458-11-140

[38] Kanungo, S., Khan, Z., Ansari, M.A. and Abedi, A.J. (2015) Role of Socio-Demographic Factors in Tuberculosis Treatment Outcome: A Prospective Study in Aligarh, Uttar Pradesh. Annals of Tropical Medicine and Public Health, 8, 55-59. http://dx.doi.org/10.4103/1755-6783.157629

[39] Ofoegbu, O.S. and Odume, B.B. (2015) Treatment Outcome of Tuberculosis Patients at National Hospital Abuja, Nigeria: A Five Year Retrospective Study. South African Family Practice, 57, 50-56. http://dx.doi.org/10.1080/20786190.2014.995913

[40] Ukwuaja, K.N., Ifebunadu, N.A., Osakwe, P.C. and Alobu, I. (2013) Tuberculosis Treatment Outcome and Its Determinants in a Tertiary Care Setting in South, Eastern Nigeria. Nigerian Postgraduate Medical Journal, 20, 125-129.

[41] Oshi, D.C., Oshi, S.N., Alobu, I. and Ukwaja, K.N. (2014) Profile, Outcomes and Determinants of Unsuccessful Tuberculosis Outcomes among HIV-Infected Tuberculosis Patients in a Nigerian State. Tuberculosis Research and Treatment, 2014, Article ID: 202983. http://dx.doi.org/10.1155/2014/202983

[42] Mukhopadhyay, S., Sarkar, A.P. and Sarkar, S.A. (2010) Study of Factors Influencing Treatment Outcome of Failure Patient Receiving DOTS in a District of West Benjul. Indian Journal of Public Health, 54, 22-23. http://dx.doi.org/10.4103/0019-557X.70541

[43] Talay, F., Kumbetti, S. and Altin, S. (2007) Factors Associated with Treatment Success for Tuberculosis Patients: A Single Centre's Experience in Turkey. Japanese Journal of Infectious Diseases, 61, 25-30.

[44] Njepuome, N. and Odume, B. (2009) The Impact of HIV Syndromes on the Treatment of TB Cases in Gombe State Nigeria. African Journal of Respiratory Medicine, 5, 17-20.

[45] Dagnra, A.Y., Adjoh, K., Tchaptchet, H.S., et al. (2011) Prevalence of HIV-TB Co-Infection and Impact of HIV Infection on Pulmonary Tuberculosis Outcome in Togo. Bulletin de la Société de Pathologie Exotique, 104, 342-346. http://dx.doi.org/10.1007/s13149-010-0079-3

[46] Basset, I.V., Chetty, S., Wang, B., Mazibuko, M., Giddy, J., Lu, Z., Walensky, R.P., Freedberg, K.A. and Losina, E. (2012) Loss to Follow up and Mortality among HIV Infected People Co-Infected with Tuberculosis at ART Initiation in Durban, South Africa. Journal of Acquired Immune Deficiency Syndromes, 59, 25-30. http://dx.doi.org/10.1097/QAI.0b013e31823d3aba

[47] Kish, L. (1965) Survey Sampling. John Wiley and Sons Inc., New York.

[48] Mohrana, P.R., Statapathy, D.M., Saham, N.C., Behera, T.R., Jena, D. and Tripathi, R.M. (2009) An Analysis of Treatment Outcome among Tuberculosis Patients Put under DOTS at Tertiary Level Health Facility of Orrisa. Journal of Community Medicine, 5, 1-10.

[49] Dim, C.C. and Dim, N.R. (2013) Trends of Tuberculosis Prevalence and Treatment Outcome in an under Sourced Setting: The Case of Enugu State, South East Nigeria. Nigerian Medicine Journal, 54, 392-397. http://dx.doi.org/10.4103/0300-1652.126292

[50] Davis, P.D. (1999) The Effects of Poverty and Aging on the Increase in Tuberculosis. Monaldi Archives for Chest Disease, 54, 168-171.

[51] Omotosho, B.A., Adebayo, A.M., Adeniyi, O.O., Ilasanmi, O.S., Kareem, A.O., Akitikori, O.T. and Erharbor, G.E. (2014) Tuberculosis Treatment Outcomes and Interruption among Patients Assessing DOTS Regimen in a Tertiary Hospital in Semi-Urban Area of South Western Nigeria. Nigerian Journal of Medicine, 23, 51-56.

[52] Egbewale, B.E., Taiwo, S.S., Odu, O.O., Olowu, O.A. and Sobaloju, S.O. (2007) Tuberculosis Treatment Outcomes in State Hospital, Osogbo, South Western Nigeria: A Four Year Review. Nigeria Journal of Medicine, 16, 148-155. http://dx.doi.org/10.4314/njm.v16i2.37298

[53] Abdool Karim, S.S., Churchyard, G.J. and Quarraisha, A. (2009) HIV Infection and Tuberculosis in South Africa: An Urgent Need to Escalate the Public Health Response. Lancet, 374, 921-933. http://dx.doi.org/10.1016/S0140-6736(09)60916-8

[54] Macpherson, P., Dimairo, M., Bandason, T., et al. (2011) Risk Factors for Mortality in Smear-Negative Tuberculosis 
Suspects: A Cohort Study in Harare Zimbabwe. The International Journal of Tuberculosis and Lung Disease, 15, 1390-1396. http://dx.doi.org/10.5588/ijtld.11.0056

[55] Oge, O.K., Fashina, A.A. and Asuzu, M.C. (2010) Evaluation of the Tuberculosis Control Programme in a South Western State, Nigeria. Journal of Community Medicine \& Primary Health Care, 22, 41-46.

[56] Ukwaja, K.N., Alobu, I., Ifebunandu, N.A., Osakwe, P.C. and Igwenyi, C. (2012) Trends in Treatment Outcomes of Smear-Positive Pulmonary Tuberculosis in South Eastern Nigeria: 1999-2009. Italian Journal of Public Health, 9, e8660.

[57] Borgdoff, N.W., Nagelkerke, N.J., Dye, C. and Num, P. (2000) Gender Differences and Tuberculosis: A Comparison of Prevalence Surveys with Notification Data to Explore Sex Differences in Case Detection. The International Journal of Tuberculosis and Lung Disease, 4, 123-132.

[58] Vijay, S., Kumar, P., Chauhas, S., Rao, S.V. and Vaidyanathan, P. (2011) Treatment Outcome and Mortality at One and Half Year Following of HIV Infected TB Patients under TB Control Program in a District of South India. PLoS ONE, 6, e 21008

[59] Ismail, I. and Bulgiba, A. (2013) Determinants of Unsuccessful Tuberculosis Treatment Outcomes in Malaysian HIVInfected Patients. Preventive Medicine, 57, S27-S80. http://dx.doi.org/10.1016/j.ypmed.2012.12.023

[60] Tweya, C., Feldacker, C., Phiri, S., et al. (2013) Comparison of Treatment Outcomes of New Smear-Positive Pulmonary Tubetculosis Patients by HIV and Antiretroviral Status in a TB/HIV Clinic, Malawi. PLoS ONE, 8, e56248. http://dx.doi.org/10.1371/journal.pone.0056248 